The research program of the Center for Economic Studiesproduces a wide range of theoretical and empirical economic analyses that serve to improve the statistical programs of the U.S. Bureau of the Census. Many of these analyses take the form of research papers. The purpose of the Discussion Papers is to circulate intermediate and final results of this research among interested readers within and outside the Census Bureau. The opinions and conclusions expressed in the papers are those of the authors and do not necessarily represent those of the U.S. Bureau of the Census. All papers are screened to ensure that they do not disclose confidential information. Persons who wish to obtain a copy of the paper, submit comments about the paper, or obtain general information about the series should contact Sang V. Nguyen, Editor, Discussion Papers, Center for Economic Studies, Room 1587, FB 3, U.S. Bureau of the Census, Washington, DC 20233-6300, $(301-763-2065)$.

\title{
MANUFACTURING ESTABLISHMENTS RECLASSIFIED INTO NEW INDUSTRIES : THE EFFECT OF SURVEY DESIGN RULES
}

By

Robert H. McGuckin*

SuZanne Peck*

CES 92-14 November 1992 


\section{Abstract}

Establishment reclassification occurs when an establishment classified in one industry in one year is reclassified into another industry in another year. Because of survey design rules at the Census Bureau these reclassifications occur systematically over time, and affect the industry-level time series of output and employment. The evidence shows that reclassified establishments occur most often in two distinct years over the life of a sample panel. Switches are not only numerous in these years, they also contribute significantly to measured industry change in industry output and employment. The problem is that reclassifications are not necessarily processed in the year that they occur. The survey rules restrict most change to certain years. The effect of these rules is evidenced by looking at the variance across industry growth rates which increases greatly in these two years. Whatever the reason for reclassifying an establishment, the way the switches are processed raises the possibility of measurement errors in the industry level statistics. Researchers and policymakers relying upon observations in annual changes in industry statistics should be aware of these systematic discontinuities, discrepancies and potential data distortions.

Key Words: Survey Design Rules, LRD, Industry Output Variations, Measurement Error, Classification

*Center for Economic Studies, U.S. Bureau of the Census

The views expressed are attributable to the authors and do not necessarily reflect those of the Census Bureau. We benefitted from the comments and assistance of Raphael Corrado, Mark Doms, Timothy Dunne, Kathy Friedman, James Monahan, Sang Nguyen, Arnie Reznek, Mary Streitwieser, Kenneth Troske and participants at 
seminars at the Center for Economics Studies and the Industry Division. 


\section{INTRODUCTION}

Establishment reclassification or switch occurs when an establishment classified in one industry in one year is reclassified by the establishment or the Census Bureau into another industry in another year. Such switches can reflect real changes in economic activity at the establishment level or can result from classification mistakes made in one period being corrected in the next period. Whatever the reason for reclassifying an establishment, the way the switches are processed in the Annual Survey of Manufactures (ASM) and the Census of Manufactures (CM or census) ${ }^{1}$ raises the possibility of measurement errors in industry level shipment and employment figures over time.

An examination of the survey design rules shows that the chance of an establishment switching in a census year or the first year of an ASM panel is higher than for other years. ${ }^{2}$ Concentrating the processing of switches into particular years raises the possibility that the survey design rules are creating a time series of aggregate industry level data that is characterized by systematic discontinuities. For example, suppose an establishment switches into an industry in some year prior to a census. Because processing of the switch is postponed until the census year the output series in the new (old) industry will be understated (overstated) throughout the period until the switch is processed. At that time, output in the industry increases (decreases) to reflect the switched establishment's output and growth.

1 The census is a quinquennial survey of the universe of manufacturing establishments in the U.S.. The ASM is an annual survey of a sample of these establishments. The ASM sample is drawn from the most recent census and weighted to represent all industries in manufacturing. An establishment remains in the sample for five years.

2 In their previous analysis of establishment reclassification from 1977 to 1982, McGuckin and Peck (1991) found that reclassifications were concentrated in 1982, a census year. 
A key issue is whether the processing of switches adds sufficient measurement error to sectoral aggregates to effect conclusions drawn from analysis based on the data. Griliches and Siegel (1990) find that a measure of four-digit industry switching activity based on a sample of continuously operating establishments in the 1972-1986 period is uncorrelated with industry productivity growth measures developed at the industry level. Baily, Campbell, and Hulten (1992) find similar evidence: switching establishments in their sample of 23 industries do account for only a small fraction of industry productivity trends, suggesting that productivity measures are not systematically related to switching activity. However, productivity measures are fundamentally the difference between output and input growth. Since both output and input measures are subject to the effects of the survey design rules, the errors may be large for each series separately, but cancel out when the productivity difference is calculated.

In this paper we focus on the effect of survey design rules on fluctuations in industry level output and employment over the 1972-1988 time period. We use the establishment-level data over time which is available in the Longitudinal Research Database (LRD). On average, we find that switching establishments in most years account for ten to fourteen percent of the annual changes in industry output. However, we find switching establishments account for 27 to 33 percent of the average four-digit industry's output change in census years. The effect of switches on employment is similar. The last part of this paper relates the effect of switching seen in the LRD to the published numbers. The concern is whether switching behavior seen in the LRD can also be seen in the published numbers. We find that the variance across industry growth rates based on both shipments and employment, is over three times larger in census years than in noncensus years. For published data the variances are smaller than those of the LRD in census years, however, they are still at least twice 
as large as variances in noncensus years. The processing rules appear to add systematic changes in both the LRD and published industry time series.

The rest of the paper is organized as follows. Section I presents the data and data collection procedures, lays out the survey design rules, and compares published and LRD industry estimates. Section III examines the extent and effect of switching activity on the manufacturing sector. This section spells out the measurements used in analyzing the impact of establishment switching and presents the effect on the proportion of and total change in an industry output and employment due to switching. The variance across industry growth rates are calculated and used to compare the results using the LRD to the published totals. Finally, section IV presents our conclusions.

\section{DATA AND SURVEY PROCESSING RULES}

We examine two types of industry switches in this paper. Switches INTO manufacturing industry $k$ are establishments whose primary activity is classified in manufacturing industry $j$ in period one, but in period two they change primary activities and are reclassified to industry $k$. Analogously, switches OUT of industry $k$ are manufacturing establishments classified in $k$ in the first period and reclassified to $j$ in the second period.

In our analysis all other establishments in an industry that do not switch are categorized as births, deaths or continuing establishments. A birth establishment is a nonswitching entrant into a manufacturing industry. Similarly, a death is a nonswitching exit from an industry. A continuing establishment remains in the same industry over the two periods.

\section{The Database and Establishment Classifications}


The Longitudinal Research Database (LRD) contains establishment-level production data. ${ }^{3}$ These data are obtained from three ASM sample panels, 19741978, 1979-1983 and 1984-1989, and six censuses, 1963, 1967, 1972, 1977, 1982 and 1987. Each census contains roughly 350,000 establishments while the ASMs contain 50,000 to 70,000 establishments. Generally, establishments with 250 or more employees are included in the ASM panel with certainty, i.e., a probability weight of one. Smaller mail or non-certainty establishments' selection to the ASM panel is based on size. To reduce the reporting burden on smaller firms, noncertainty ASM cases are rotated out of the panel after five years. Consequently, only large establishments are included in consecutive ASM sample panels. ${ }^{4}$ New ASM panels are chosen two years after a census and are weighted to reflect the industry composition of the previous census from which the sample is selected. For example, the 1979 ASM panel reflects the industry composition in the 1977 census.

Each establishment in the LRD is assigned a 4-digit standard Industrial Classification (SIC) code corresponding to the establishment's primary activity. If the primary activity of an establishment changes, its SIC code changes and a switch occurs. For example, consider an establishment whose shipments in year one equal 51 percent butter and 49 percent cheese. This establishment is classified in the butter industry, its primary activity. All employment and output for this establishment are included in the butter industry's totals. In year two, the establishment's cheese shipments increase to equal 51 percent of total shipments. Cheese becomes the establishment's new primary activity and as a result the establishment is reclassified into

3 The LRD contains confidential Census Bureau information and is accessible to researchers through the Center for Economic Studies (CES) of the U.S. Census Bureau. For a more complete description of the LRD see McGuckin and Pascoe (1988). small firms.

4 Exceptions exist in some industries which are composed mostly of very 
the cheese industry. Now, all employment and output of the establishment are part of the cheese industry's aggregate numbers. This establishment switched OUT of the butter industry and switched INTO the cheese industry.

In this study we concentrate on changes in the 4-digit or industry-level SIC code of an establishment. The extensive changes in the SIC codes in 1987 necessitate our using only those 361 industries with consistent definitions from 1972 to 1988. Arguably, these 361 industries are relatively stable and well defined and therefore, less likely to generate switches because of poorly defined industries. We also find fewer switches because of how we count switches across these 361 industries. We consider an establishment that switches out of one of the 361 industries into another manufacturing industry not included in this group as a death. Likewise, establishments switching into our group of industries from another manufacturing industry are defined as births. Thus, our procedures minimize the volume of observed switches across all of manufacturing. ${ }^{5}$

\section{Survey Design Rules}

Occasions exist where the primary activity of an establishment changes, yet its industry code remains unchanged. The resistance rule and the design of the ASM survey forms ensure that most reclassifications are processed at two points in time, in census years and in the first year of a new ASM panel. Also in census years corrections from previous mistakes in coding are processed. 6

5 See McGuckin and Peck (1991) for similar analyses as seen in this paper using 441 industries from 1972-1983.

6 All nonASM establishment reclassifications are processed in CM years. 
The resistance rule affects the timing of certainty establishment switches during the five years of an ASM sample panel (See Appendix for precise rules). Certainty establishments in the ASM panel only switch industries when they show a shift in their primary activity, and that shift meets the restrictive guidelines of the rule. Some large establishment switches not meeting the guidelines are deferred until a new ASM panel is drawn. ${ }^{7}$ Noncertainty ASM establishments generally remain unchanged until census years when they may switch freely. Establishments surveyed only in the census are unaffected by the resistance rule. This rule causes most switches to occur in census years and the first year of as ASM panel.

Survey collection procedures dictate that detailed seven-digit SIC product data are only collected in census years. Thus, reclassifications arising from new product structures are often not recorded until the census. The design and length of survey forms sent out annually to ASM establishments are shorter than those sent out in census years. In ASM years establishments receive forms specific to the particular industry in which they are classified. The form contains general descriptions of product groups (5-digit product codes) for that industry. An establishment's output (TVS) and employment (TE) ${ }^{8}$ is

7 The resistance rule is designed to maintain continuity in the establishment composition of an industry, balancing the desirability of showing true economic activity occurring in the industries with the advantages of maintaining a consistent weighting scheme for the sample. The butter and cheese example described earlier illustrates why the Census Bureau uses the resistance rule. In the example, the shipments of the establishment change very little in terms of percentage of products produced yet if a switch is allowed all of its TVS, TE, etc. is reclassified into a new industry. The following year the establishment could easily switch back into the butter industry. The resistance rule tries to avoid simple flip-flops in industries.

8 TVS in manufacturing is the sum of product values, receipts from contract work performed for others, sales of products bought and sold without further processing and miscellaneous receipts for installation and repair work, sales of scrap, etc. TE records the sum of the average number of production workers for the mid-month payroll periods of March, May, August, and November and the number of non-production personnel employed during the pay period including the 12th of march. (Longitudinal Research Database Technical Documentation Manual, 1992) 
distributed into these product groups. In census years, the same establishment receives a form with detailed listings of primary and secondary products (7-digit product codes) for its present industry plus products of related industries. Some forms may contain as many as six industries' lists of products. This expanded choice leads to better reporting of changes in product structures and thereby causes establishment switches to be more concentrated in census years. ${ }^{9}$ As streitwieser (1991) reports, there have been substantial changes in establishment product structures over time.

Additional switches occur in census years from reviewing establishments classified in the "Not Elsewhere Classified" (NEC) industries. NEC industries serve as catch-alls for activities not fitting into another industry or for establishments with ill-defined primary activities. All establishments including those classified in NEC industries are more closely reviewed in census years. The additional information provided on a survey form better identifies an establishment's primary activity which in some cases may lead to a switch out of an NEC industry.

\section{Published Data Versus LRD Aggregations}

The LRD provides the level of disaggregation needed to analyze establishment switching behavior in industries. However, the industry totals obtained from the LRD do not perfectly match the published numbers available to most researchers. Since a major objective of this paper is to examine the effects of switches on published aggregates, it is important to describe differences

9 For example, a small establishment indicates that it does steel metalwork and is classified in industry 331, "Steel Works, Blast Furnaces, and Rolling and Finishing Mills." The establishment is added to the ASM and sent a form for industry 331. However, when surveyed with the more detailed from in the census, it is discovered that the establishment actually produces in industry 346, "Metal Forgings and Stampings." The establishment is reclassified to industry 346 and a switch occurs. 
between the aggregate numbers developed from the LRD and those published by the Census Bureau. ${ }^{10}$

Figure 1 compares TVS in manufacturing between the LRD and the published data (PD). The "PD minus LRD" line shows how these two series have been increasingly diverging over the years and converging in census years. The difference between the published data and LRD based totals is associated with the methodology used in estimating industry totals (PD) from collected data (LRD). In all years but census years, the LRD is the weighted sum of the ASM establishments' TVS. The published data includes the LRD totals plus small establishment imputations and fixed based difference adjustments, a statistical adjustment to account for sampling error. These adjustments represent the difference in the two series in noncensus years. The two series converge in census years because both are aggregates from the universe of establishments.

After 1979, the LRD and published data increasingly diverge in response to reductions in the ASM sample size and increased reliance on small firm imputations. The pattern observed in figure 1 from 1977-1982 clearly reflects a monotonically increasing understatement of total output in the LRD based aggregates which are calculated from deteriorating ASM panels. Since 1983 is based on the 1979 ASM panel, the relatively high deviation is simply a continuation of the panel deterioration reflected in the 1979-1981 deviations shown in figure 1. The 1984-1986 deviation shows the same monotonic increase in difference, albeit at a higher level than that found for the 1979-1981 period. Again for 1988, the last year of the panel, the two time series deviate. This problem leads to growth during census years being generally overstated because the pre-census ASM totals are too low.

10 The relationships between the LRD and published figures are examined extensively in Davis, Haltiwanger, and Schuh (1990). They also provide a detailed explanation of how ASM estimates are generated. 
In order to ensure that our analysis identifies the impact of switches and is not distorted by the differences between published and LRD industry totals, we develop our empirical analysis in two ways: on the basis of census to census universe comparisons and on the basis of estimates of yearly totals based on ASM sample cases alone. In the case of census to census comparisons we deal with universe values that should not be affected by sampling error. For the case of annual comparisons, we exclusively use the totals obtained by weighting up ASM cases, even in census years. This avoids distortions associated with growth rates calculated on deteriorating ASM panels that cause intercensal changes to be concentrated in census years. This method should isolate the effects due to switching.

\section{THE EXTENT AND EFFECTS OF SWITCHING ACTIVITY IN MANUFACTURING INDUSTRIES}

In this section, we describe the measures used in assessing the extent and effects of reclassification. The results of the proportion of total value of shipments (TVS) and total employment (TE) switching in one year, evidence of the resistance rule, and the effect of switches on industry change in TVS and TE follow. Finally, we link these results to the published estimates by looking at the effect of reclassification on the variance of industry growth rates.

\section{Measures}

We use two sets of measures in evaluating the extent of reclassifications. The first compares the proportion of TVS and TE switching to the industry totals in a single year. Next, year to year comparisons are made by measuring the portion of total change in TVS or TE accounted for by establishments switching in and out of an industry. To see if large industries are dominating the analysis we weight the statistics by industry TVS. 
The following notation is used in our analysis: $T V S_{j}$ and $T E_{j}$ are total value of shipments and total employment, respectively, in industry j. The years we consider are $t$ and $t-1$. The superscript si denotes switch in, so denotes switch out, b denotes establishment births, $d$ denotes establishment deaths, and $c$ denotes continuing establishments.

First we measure the proportion of TVS switching out of the industry from year t-1 to total industry TVS in year $t-1, L T V S_{j}^{\text {so }}=T V S_{j}^{\text {so }} / T V S_{j}(t-1)$. Similarly, we compare the proportion of TVS switching into the industry in year $t$ to total industry TVS in year $t, L T V S_{j}^{s i}=T V S_{j}^{s i} / T V S_{j}(t)$. The proportion of TE switching, $L T E_{j}^{s o}$ and $L T E_{j}^{s i}$, is also calculated, providing an initial indication of the magnitude of switching activity in manufacturing.

The second set of measures focuses on the impact of switching on year to year changes in industry output of employment. Changes in TVS or TE in an industry are decomposed into three parts: change associated with switching, birth/death, and continuing establishments. Since change in each of these categories may be positive or negative, we sum the absolute values of change in each category to obtain a measure of total industry change. For industry $j$ for TVS,

$$
T C_{j}^{T V S}-\left|T V S_{j}^{s i}-T V S_{j}^{s o}\right|+\left|T V S_{j}^{b}-T V S_{j}^{d}\right|+\left|\Delta T V S_{j}^{c}\right|
$$

where $T C_{j}^{\mathrm{TVS}}$ is the total change in TVS in industry $j$. Similarly, $T C_{j}^{\mathrm{TE}}$ is the total change in $\mathrm{TE}$ in industry $j$. The proportion of $T C_{j}^{\mathrm{TVS}}$ associated with switches is given as

$$
P_{f}^{T V S}(s)-\left|T V S_{f}^{s i}-T V S_{f}^{s o}\right| / T C_{J}^{T V S}
$$


Similarly, $P_{j}^{\mathrm{TVS}}(b)$ and $P_{j}^{\mathrm{TVS}}(c) \quad\left(P_{j}^{\mathrm{TE}}(b)\right.$ and $\left.P_{j}^{\mathrm{TE}}(c)\right)$ represent the proportion of $T C_{j}^{\mathrm{TVS}}\left(T C_{j}^{\mathrm{TE}}\right)$ associated with birth/death and continuing establishments, respectively

\section{Switches and the Proportion of Industry Activity}

Table 1 presents the industry averages of the proportion of TVS (LTVS $S_{j}^{s i}$, $L T V S_{j}^{s o}$ ) and $\operatorname{TE}\left(L T E_{j}^{s i}, L T E_{j}^{s o}\right.$ ) associated with switches. Columns (A) and (B) present simple averages over 361 industries while columns (C) and (D) present averages weighted by industry size measured by TVS.

On average eight percent of the shipments in one census switch out in the next census. The average percentage of employees switching out in a census is closer to nine percent. The weighted proportions for the industries are below unweighted proportions at around 6 percent for output in each census year. This indicates that switching is more heavily concentrated in smaller industries. The gross level of switching activity implied by the numbers in table 1 is large. The average industry between 1977 and 1982 had 17 percent of its TVS and 18 percent of TE reclassified.

For annual changes, we also see a distinct pattern in the proportion of TVS switching in and out of the average industry. Consistently, the greatest amount of change is concentrated in the census years. For instance, between 1981 and 1982 over seven times as much TVS switches out of the average industry then between 1980 and 1981 and other ASM years. Similar results occur for switching in. Looking at results for TE yields similar conclusions.

\section{Establishments that Switch Under the Resistance Rule}

The resistance rule states that certainty plants may switch if they meet certain criteria and noncertainty plants may switch in census years. Table 2 shows all ASM plants switching in each panel by type of plant. Consistent 
with table 1, most ASM switches occur in census years. More importantly, this table shows that certainty plants represent the majority of switches except in census years. Very little switching occurs among noncertainty plants except in census years as the resistance rule dictates.

The second greatest number of plants switching is in the first year of an ASM panel, 1973-74, 1978-79 and 1983-84. ${ }^{11}$ When a new ASM panel is selected because of the resistance rule we also expect to see many switches in both types of plants. Certainty plants represent the largest portion of switching plants in these years. The noncertainty plants although not as large of a percentage as the certainty plants still represent the greatest concentration of noncertainty plants switching over the panel years.

Measuring the effect of switches in terms of TVS and TE between panel years becomes difficult because of the sampling weights assigned to the plants. Weights for a plant may vary from panel to panel making it difficult to create proper estimates of industry statistics. In this paper we do not attempt to solve this problem and as a result do not present statistics for these first years of an ASM panel in tables 1, 3A, and 3B. We can only surmise from the greater counts of switches in these years that we would find higher proportions of TVS and TE than found in table 1 for all other years except census years. Similarly, these proportions would probably be lower than in census years.

\section{Importance of Switches to Change in TVS and TE}

11 These counts were obtained by first comparing industry codes of plants in both the new and old panels. Unmatched plants from the new panel were then matched with the previous census year, the universe from which this panel was selected. For instance, some plants were matched from the old panel in 1973 to the new panel in 1974. Those plants in the 1974 that failed to match were linked to the 1972 census. 
The averages of $P_{j}(s), P_{j}(b)$ and $P_{j}(c)$ across all 361 industries are presented in tables $3 A$ and $3 B$. This allows us to compare the extent to which switching, continuing, and birth/death establishments affect change in TVS and TE for the average industry between two years. Table 3A provides unweighted proportions and table 3B provides weighted proportions. As with table 1, the proportions are provided on both a census to census basis and an annual basis. Between census years, switches account for about 15 percent of shipments change, a little less than the proportion of births and deaths $\left(P_{j}(b)\right)$. For these periods, nearly 65 percent of the change in TVS is associated with continuing establishments $\left(P_{j}(C)\right)$ and this reaches 71 percent when weighted by TVS. Switches are a much larger component of employment change than in TVS in these periods. Switches account for about 25 percent and continuing establishments for 49 percent of the change in TE. The TE figures are about the same whether weighted or not. As with the output, the greatest proportion of change between two census years comes from the continuing establishments.

The results for annual changes are complementary. In the census years, 197677, 1981-82, and 1986-1987, switches account for more than twice the total change $T C_{j}$ in TVS and TE than in the previous years. In these years the proportion of total change associated with continuing establishments falls dramatically, to levels below 50 percent. Thus, the composition of establishments accounting for output and input change alters dramatically in census years.

There is some evidence that the importance of switches has increased over time. Switches occurring between 1972 and 1977 represent a smaller portion of the total change in TVS (13 percent) than those in between 1977 and 1982 (16 percent) and between 1982 and 1987 (17 percent). The weighted numbers show virtually no difference between 1972-77 and 1977-82 but show a sharp increase in 1982-87. However, the portion attributable to TE shows small declines over 
the period both on a weighted and unweighted basis. Nonetheless, the proportion of employment change accounted for by switches is higher when compared to output in all periods.

\section{The Effect of Processing Rules on the Variance of Industry Growth Rates}

Switching activity accounts for a substantial proportion of output change in an average industry. This micro-level analysis is interesting and we now explore how these findings influence the published data. We compute the variance of growth rates across industries and plot these variances over time for the LRD and published data. Since establishments most often change their industry code in the first year of an ASM panel and in census years, we expect to observe unusual growth rates and as result observe increased variances in growth rates in these years.

Growth rates for output, GR, are calculated by $\mathrm{GR}_{\mathrm{t}}=\left[\mathrm{TVS}_{\mathrm{t}+1}-\mathrm{TVS}_{\mathrm{t}}\right] / \mathrm{TVS}_{\mathrm{t}}$, for each year, t, from 1972 to 1988 for each industry. For each group of years, i.e., 78-79, the variance of growth rates across all 361 industries is computed. Figure 2 displays the variances across time based on both the published data (PD) and the LRD. Most noticeable in both series are the substantially greater variances in census years (76-77, 81-82, 86-87) than for the years in between. Output totals in the LRD and PD in census years (77, 82, 87) are aggregated statistics from the total universe of establishments surveyed in that year. These totals represent the most up-to-date composition of industries including all establishments that have switched into new industries or from old ones. Output totals for the year before a census year (76, 81, 86) are estimated from statistics collected from an ASM sample based on a five-year-old mix of industries from the previous census (72, 77, 82). In census years the distribution of growth rates increases as the growth rates in many industries are calculated from an underestimate of industry output in year $t$ to a true estimate in year $t+1$. 
For the LRD, the ASM years (73-74, 78-79, 83-84) also show higher variances. ${ }^{12}$ Similar to the effect in census years, the estimates calculated from the last year of an ASM panel are underestimated because of a deteriorating panel. Despite adjustments made based on the census the year before (72, 77, 82), the last year of the sample represents the structure of manufacturing from six years before $(67,72,77)$. The new panel represents manufacturing from just two years ago. This exaggerated pattern in the last year of an ASM panel is not evident in the published numbers. The adjustments to the ASM estimates starting in 1979 seem to smooth variances over time and as result smooth the year to year effects. ${ }^{13}$

Figure 3 shows the time trend of the variance of growth rates substituting the value calculated from using only weighted ASM plants for those based on the total universe of establishments in census years. The LRD TVS line is the same in both figures 2 and 3. By eliminating the effect of using the total universe of establishments in census year and using only AsM establishments creates less change in the distribution of the growth rates and as a result lower variance estimates in census years. However, this variance is still higher than other years. Eliminating the effect on growth rates due to going from estimates based on the deteriorating panel to population totals better isolates the effect due to switching establishments. Even with this adjustment, figure 3 shows switches accounting for a good portion of the higher variance in census years.

For both series in figure 2, the variance of growth rates show substantially higher values in 1987 than in 1977 (.08 versus .03 for the LRD and .05 versus

12 The large variance in TVS for 1974 decreases when we use price deflators to eliminate any effect due to oil price shocks.

13 For published totals, we weighted each industry growth rate by industry TVS. After accounting for large industries the same pattern emerged except with smaller variances. 
.025 for the published values). We offer one explanation. Unlike in 1977 or 1982, the classification system was greatly revised in 1987 . New industries were created and old industries were scaled back to represent the evolution of manufacturing. Although the 361 industries used in this analysis maintain reasonably consistent definitions over time, many of these industries still added and deleted products. The survey forms reflected this change by including new products and as a result many establishments changed their industry classification. We do see in table 3A a greater proportion of total change in output accounted for by switching establishments in 1986-87 then in 1976-77 or 1981-82. It will be interesting to see if the pattern of increased variances continues in 1991-92.

\section{CONCLUSION}

Establishment reclassifications occur systematically over the period 1972 to 1987, and these affect the industry-level time series of output and employment figures. Evidence shows that reclassified establishments are most numerous in census years and in the first year of a new ASM panel. They represent about eight percent of the TVS and nine percent of TE in the average industry present between censuses. Since a reclassification represents turnover in two industries, the one switched into and the one switched out of, the impact of switches on the composition of particular industries is significant.

We also find that switches are not only numerous, they also contribute significantly to measured industry change in TVS and TE particularly in census years. Switches represent greater than one-third of the total change in an industry in census years. Even after accounting for the effect of calculating growth rates from underestimated to true industry totals, the variance in industry growth rates due to switches still causes systematic effects in the time series. These effects also appear, though to a lesser degree, in the published numbers series. 
Whatever the reason for reclassifying an establishment, the way the switches are processed in the ASM and census raises the possibility of measurement errors in the industry level time series of shipment and employment figures. Researchers and policymakers relying upon observations in annual changes in industry statistics should be aware of these systematic discontinuities, discrepancies and potential data distortions. 


\section{REFERENCES}

Andrews, S.H. and T.A. Abbott, III. (1990). "The Classification of Manufacturing Industries: An Input-based Clustering of Activity," U.S. Bureau of the Census Annual Research Conference Proceedings.

Andrews, S.H. and T.A. Abbott, III. (1988). "An Examination of the Standard Industrial Classification of Manufacturing Activity Using the Longitudinal Research Database," U.S. Bureau of the Census Fourth Annual Research Conference Proceedings.

Baily, M.N., C. Hulten, and D. Campbell. (1992). "Productivity Dynamics in Manufacturing Establishments," Brookings Papers on Economic Activity: Microeconomic, 1992, 187-267.

Baldwin, J.R. and P.K. Gorecki. (1990a). "Firm Entry and Exit in the Canadian Manufacturing Sector," Research Paper \#767, Institute for Economic Research, Queen's University, Ontario.

Baldwin, J.R. and P.K. Gorecki. (1990b). "Measuring Entry and Exit to the Canadian Manufacturing Sector Using Longitudinal Data: Methodology," A.C. Singh ed. Analysis of Data in Time. Proceedings of a Conference sponsored by Statistics Canada, Carleton and Ottawa University, Fall 1989 .

Davis, S., J. Haltiwanger and S. Schuh. (1990). "Published Versus Sample Statistics from the ASM: Implications for the LRD" Proceedings of the American Statistical Association, Business and Economics Section.

Dunne, T. and M. Roberts. (1986). "Measuring Firm Entry and Exit with Census of Manufactures Data," Department of Economics, The Pennsylvania State University.

Dunne, T., M. Roberts and L. Samuelson. (1988). "Patterns of Firm Entry and Exit in U.S. Manufacturing Industries," Rand Journal of Economics $19(4): 495-515$.

Gollop, F.M. and J.L. Monahan. (1986). "From Homogeneity to Heterogeneity: An Index of Diversification," Technical Paper 60, U.S. Bureau of the Census.

Griliches, Z. and D. Siegel. (1991). "Purchased Services, Outsourcing, Computers, and Productivity in Manufacturing," Working Paper Series No. 3678, National Bureau for Economic Research, Inc.

McGuckin, R.H. and G.A. Pascoe, Jr. (1988). "The Longitudinal Research Database: Status and Research Possibilities," Survey of Current Business, Vol. 68, No. 11 (November), pp. 30-37.

McGuckin, R.H. and S. Peck. (1991). "An Examination of Reclassified Manufacturing Establishments," Proceedings of the American Statistical Association, Business and Economics Section.

Ogus, J.L. and D.F. Clark (1971), "The Annual Survey of Manufactures: A Report on Methodology," Technical Paper No. 24, U.S. Department of Commerce, Bureau of the Census. 
Streitwieser, M.L. (1991). "The Extent and Nature of Establishment Level Diversification in Sixteen U.S. Manufacturing Industries," Journal of Law and Economics vol. 34, no. 2, pt. 2:503-34.

U.S. Office of Management and Budget. (1987). Standard Industrial Classification Manual, Government Printing Office, Washington, D.C. 
TABLE 1

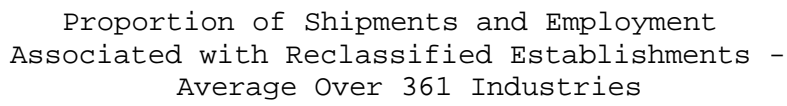

Proportion of Shipments and Employment Associated with Reclassified Establishments Average Over 361 Industries

$\begin{array}{rrr}\text { Year } 1 & \text { Year } 2 & \begin{array}{l}\text { Unweighted } \\ \text { Switch Out } \\ \text { Year } 1\end{array}\end{array}$

(A)
Switch In

Year 2

(B)
Weighted Switch Out Year 1

(C)
Switch In

Year 2

(D)

SHIPMENTS ( $\operatorname{LTVS}_{j}^{\mathrm{so}}, \operatorname{LTVS}_{j}^{\mathrm{si}}$ )

$\mathrm{CM}$ to $\mathrm{CM}$

1972

1977

1977

1982

0.0880

0.0811

0.0870

0.0891

0.0836

0.0865

0.0603

0.0551

0.0606

1982

1987

0.0306

0.0194

0.0101

0.0114

0.0753

0.0046

0.0075

0.0087

0.0107

0.0095

0.0113

0.0765

0.0814

1982

1983

1982

1985

1986

1987

1988

0.0094

0.0111

0.0089

0.0105

0.0115

0.0758

0.0206

0.0179

0.0609

0.0582

0.0156

0.0083

0.0520

0.0036

.0161

0.0089

0.0512

0.0035

$0.0061 \quad 0.0073$

$0.0070 \quad 0.0068$

$0.0486 \quad 0.0480$

$0.0059 \quad 0.0061$

$0.0103 \quad 0.0088$

$0.0088 \quad 0.0096$

$0.0541 \quad 0.0516$

$0.0137 \quad 0.0106$

EMPLOYMENT (LTE $\left.E_{j}^{\text {So }}, L T E_{j}^{\text {si }}\right)$

CM to $\mathrm{CM}$

$\begin{array}{ll}1972 & 1977 \\ 1977 & 1982 \\ 1982 & 1987 \\ & \\ \text { ASM to ASM } & \\ 1974 & 1975 \\ 1975 & 1976 \\ 1976 & 1977 \\ 1977 & 1978 \\ & \\ 1979 & 1980 \\ 1980 & 1981 \\ 1981 & 1982 \\ 1982 & 1983 \\ 1984 & \\ 1986 & 1985 \\ 1986 & 1987 \\ 1987 & 1987 \\ & 1988\end{array}$

0.0912

0.0901

0.0647

0.0637

0.0871

0.0940

0.0595

0.0625

0.0885

0.0711

0.0602

0.0320

0.0189

0.0166

0.0166

0.0111

0.0107

0.0793

0.0085

0.0089

0.0794

0.0063

0.0037

0.0032

0.0089

0.0087

0.0106

0.0105

0.0873

0.0084

0.0099

0.0067

0.0074

0.0062

0.0553

0.0070

0.0079

0.0566

0.0094

0.0078

0.0115

.0062

0.0105

0.0099

0.0075

0.0079

0.0893

0.0874

0.0618

0.0101

0.0198

0.0176

0.0159 
Establishments in 361 Industries that Switch Out by Panel Year, by Type by Year

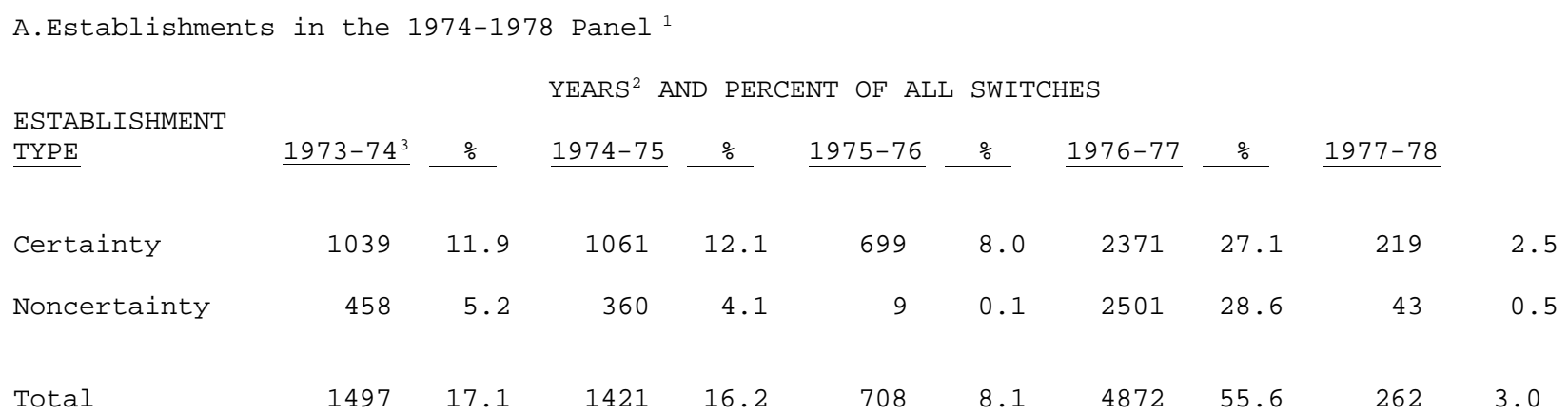

B. Establishments in the 1979-1983 Panel

\begin{tabular}{|c|c|c|c|c|c|c|c|c|c|}
\hline & $1978-79^{3}$ & $\%$ & 1979-80 & $\%$ & $1980-81$ & $\%$ & $1981-82$ & $\%$ & $1982-83$ \\
\hline Certainty & 947 & 14.9 & 474 & 7.5 & 423 & 6.7 & 1508 & 23.7 & 412 \\
\hline Noncertainty & 125 & 2.0 & 13 & 0.2 & 13 & 0.2 & 2436 & 38.3 & 5 \\
\hline Total & 1072 & 16.9 & 487 & 7.7 & 436 & 6.9 & 3944 & 62.1 & 417 \\
\hline
\end{tabular}

C. Establishments in the 1984-1986 Panel

\begin{tabular}{|c|c|c|c|c|c|c|c|c|c|c|}
\hline & $1983-84^{3}$ & $\%$ & $\underline{1984-85}$ & $\%$ & $\underline{1985-86}$ & $\%$ & $\underline{1986-87}$ & $\%$ & $\underline{1987-88}$ & \\
\hline Certainty & 619 & 10.6 & 372 & 6.4 & 381 & 6.5 & 1646 & 28.3 & 595 & 10.2 \\
\hline Noncertainty & 299 & 5.1 & 16 & 0.3 & 11 & 0.2 & 1790 & 30.7 & 94 & 1.6 \\
\hline Total & 918 & 15.8 & 388 & 6.7 & 392 & 6.7 & 3436 & 59.0 & 689 & 11.8 \\
\hline
\end{tabular}

1 The 1974-1978 ASM panel contains about 70,000 plants whereas the other panels studied here contain about 55,000 plants. As a result, we observe greater numbers of plants switching in the 1974-78 panel. However, the percentage switching is relatively the same for all the panels.

2 This is the count of ASM plants that change industries from one year to the next, i.e. 1974-75.

3 This is a count of switches between two panels. We looked to see if plants selected for the new panel had changed industry codes from the last time they were surveyed. Some plants inform ation came from the previous year (1973, 1978, 1983) and some from the previous CM (1972, 1977, 1982). 
TABLE 3A

Proportion of Total Change in Industry Due to Three Establishment Types Average Over 361 Industries

\begin{abstract}
Birth/Death
\end{abstract}
Years

Switches

$P_{j}(s)$

Continuing

$$
P_{j}(c)
$$$$
P_{j}(b)
$$

UNWEIGHTED

\begin{tabular}{|c|c|c|c|c|c|}
\hline \multicolumn{6}{|c|}{$\mathrm{CM}$ to $\mathrm{CM}$} \\
\hline & $1972-77$ & 0.1270 & $(.133)$ & 0.6865 & $(.200)$ \\
\hline 0.1811 & $\begin{array}{l}(.151) \\
1977-82\end{array}$ & 0.1631 & $(.164)$ & 0.6466 & $(.222)$ \\
\hline 0.1903 & $\begin{array}{l}(.168) \\
1982-87\end{array}$ & 0.1705 & $(.159)$ & 0.5951 & $(.235)$ \\
\hline 0.2317 & $(.193)$ & & & & \\
\hline \multicolumn{6}{|c|}{ ASM to ASM } \\
\hline & $\begin{array}{l}1974-75 \\
(.218)\end{array}$ & 0.1791 & $(.214)$ & 0.5440 & $(.298)$ \\
\hline & $1975-76$ & 0.1025 & $(.158)$ & 0.7067 & $(.297)$ \\
\hline 0.1117 & $\begin{array}{l}(.140) \\
1976-77\end{array}$ & 0.2672 & $(.237)$ & 0.4801 & $(.287)$ \\
\hline 0.1762 & $\begin{array}{l}(.191) \\
1977-78\end{array}$ & 0.0674 & $(.150)$ & 0.6780 & $(.304)$ \\
\hline 0.1755 & $(.191)$ & & & & \\
\hline 0.1358 & $\begin{array}{l}1979-80 \\
(.178)\end{array}$ & 0.1141 & $(.170)$ & 0.7502 & $(.238)$ \\
\hline 0.1681 & $\begin{array}{l}1980-81 \\
(.182)\end{array}$ & 0.1207 & $(.177)$ & 0.7112 & $(.239)$ \\
\hline 0.2136 & $\begin{array}{l}1981-82 \\
(.200)\end{array}$ & 0.2936 & $(.237)$ & 0.4928 & $(.272)$ \\
\hline 0.2418 & $\begin{array}{l}1982-83 \\
(.235)\end{array}$ & 0.1088 & $(.178)$ & 0.6492 & $(.268)$ \\
\hline 0.2709 & $\begin{array}{l}1984-85 \\
(.237)\end{array}$ & 0.1361 & $(.199)$ & 0.5929 & $(.277)$ \\
\hline 0.2898 & $\begin{array}{l}1985-86 \\
(.236)\end{array}$ & 0.1436 & $(.207)$ & 0.5665 & $(.274)$ \\
\hline & $1986-87$ & 0.3251 & $(.227)$ & 0.4182 & $(.242)$ \\
\hline 0.2567 & $\begin{array}{l}(.205) \\
1987-88\end{array}$ & 0.1469 & $(.198)$ & 0.5917 & $(.281)$ \\
\hline 0.2614 & $(.234)$ & & & & \\
\hline & IPLOYMENT & & & & \\
\hline & I to $\mathrm{CM}$ & & & & \\
\hline 0.3691 & $\begin{array}{l}1972-77 \\
(.237)\end{array}$ & 0.2771 & $(.234)$ & 0.3483 & $(.242)$ \\
\hline & $1977-82$ & 0.2523 & $(.208)$ & 0.4420 & $(.247)$ \\
\hline 0.3057 & $(.215)$ & & & & \\
\hline 0.3587 & $\begin{array}{l}1982-87 \\
(.230)\end{array}$ & 0.2375 & $(.209)$ & 0.4011 & $(.246)$ \\
\hline & $\mathrm{M}$ to ASM & & & & \\
\hline 0.1827 & $\begin{array}{l}1974-75 \\
(.202)\end{array}$ & 0.1558 & $(.199)$ & 0.6003 & $(.292)$ \\
\hline $0.102 t$ & $1975-76$ & 0.1577 & $(.197)$ & 0.5407 & $(.298)$ \\
\hline 0.2226 & $(.220)$ & & & & \\
\hline & $1976-77$ & 0.3747 & $(.262)$ & 0.2893 & $(.240)$ \\
\hline 0.2595 & $(.226)$ & & & & \\
\hline
\end{tabular}




\begin{tabular}{|c|c|c|c|c|c|}
\hline 0.3101 & $\begin{array}{l}1977-78 \\
(.258)\end{array}$ & 0.0967 & $(.185)$ & 0.5141 & $(.304)$ \\
\hline 0.1928 & $\begin{array}{l}1979-80 \\
(.215)\end{array}$ & 0.1527 & $(.202)$ & 0.6544 & $(.268)$ \\
\hline 0.2387 & $\begin{array}{l}1980-81 \\
(.233)\end{array}$ & 0.1771 & $(.223)$ & 0.5842 & $(.284)$ \\
\hline 0.2251 & $\begin{array}{l}1981-82 \\
(.198)\end{array}$ & 0.2859 & (.219) & 0.4889 & $(.246)$ \\
\hline 0.2901 & $\begin{array}{l}1982-83 \\
(.248)\end{array}$ & 0.1332 & $(.190)$ & 0.5768 & $(.284)$ \\
\hline 0.2899 & $\begin{array}{l}1984-85 \\
(.239)\end{array}$ & 0.1422 & $(.204)$ & 0.5679 & $(.271)$ \\
\hline 0.3217 & $\begin{array}{l}1985-86 \\
(.246)\end{array}$ & 0.1498 & $(.206)$ & 0.5285 & $(.274)$ \\
\hline 0.3195 & $\begin{array}{c}1986-87 \\
(.236)\end{array}$ & 0.4012 & $(.261)$ & 0.2793 & $(.219)$ \\
\hline 0.3521 & $\begin{array}{l}1987-88 \\
(.254)\end{array}$ & 0.2114 & $(.231)$ & 0.4365 & $(.273)$ \\
\hline
\end{tabular}


TABLE 3B

Proportion of Total Change in Industry Due to Three Establishment Types Average Over 361 Industries

\begin{abstract}
Birth/Death
\end{abstract}
Years

Switches

$P_{j}(s)$

Continuing

$P_{j}(c)$

$P_{j}(b)$

WEIGHTED

SHIPMENTS

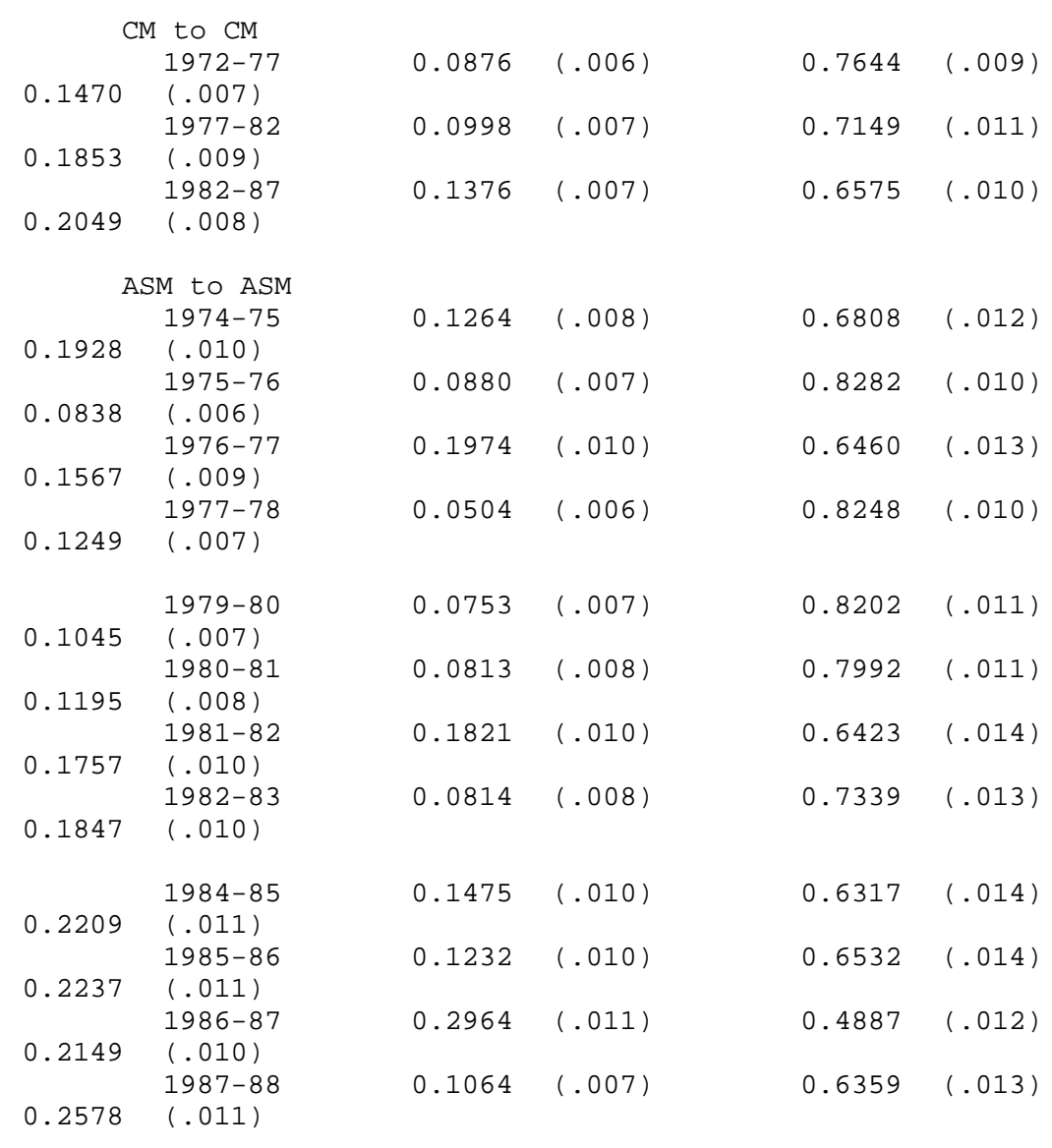

EMPLOYMENT

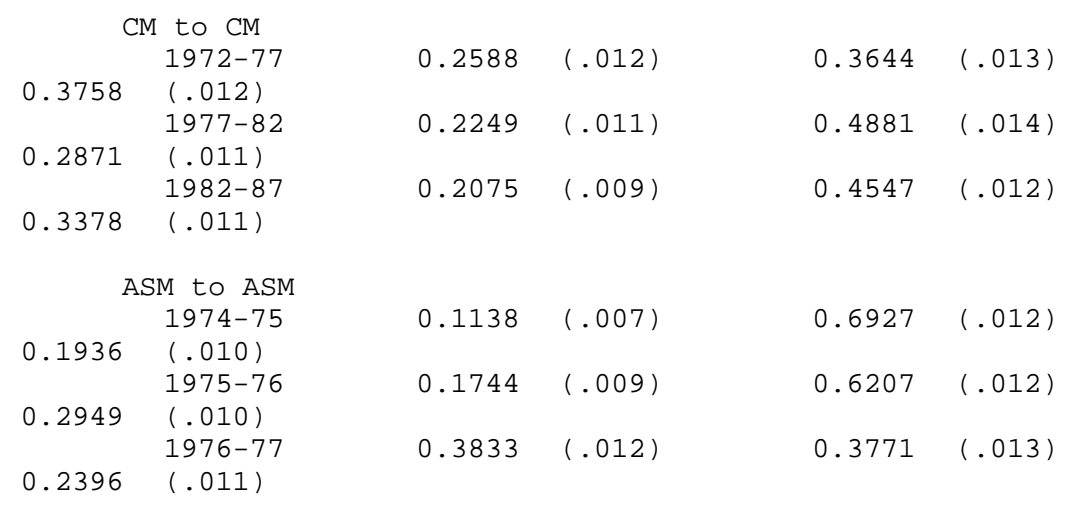




\begin{tabular}{|c|c|c|c|c|c|}
\hline 0.3244 & $\begin{array}{l}1977-78 \\
(.011)\end{array}$ & 0.0837 & $(.008)$ & 0.5919 & $(.012)$ \\
\hline 0.1913 & $\begin{array}{l}1979-80 \\
(.011)\end{array}$ & 0.1149 & $(.008)$ & 0.6938 & $(.014)$ \\
\hline 0.2112 & $\begin{array}{l}1980-81 \\
(.011)\end{array}$ & 0.1359 & $(.010)$ & 0.6528 & $(.013)$ \\
\hline 0.2292 & $\begin{array}{l}1981-82 \\
(.009)\end{array}$ & 0.2276 & $(.009)$ & 0.5432 & $(.013)$ \\
\hline 0.2576 & $\begin{array}{l}1982-83 \\
(.011)\end{array}$ & 0.1356 & $(.009)$ & 0.6068 & $(.014)$ \\
\hline 0.2554 & $\begin{array}{l}1984-85 \\
(.012)\end{array}$ & 0.1732 & $(.011)$ & 0.5714 & $(.014)$ \\
\hline 0.3039 & $\begin{array}{l}1985-86 \\
(.013)\end{array}$ & 0.1605 & $(.010)$ & 0.5356 & $(.015)$ \\
\hline 0.3089 & $\begin{array}{l}1986-87 \\
(.012)\end{array}$ & 0.3798 & $(.013)$ & 0.3112 & $(.012)$ \\
\hline 0.3438 & $\begin{array}{l}1987-88 \\
(.012)\end{array}$ & 0.2012 & $(.011)$ & 0.4551 & $(.014)$ \\
\hline
\end{tabular}




\section{APPENDIX}

The Resistance Rule

This excerpt from the 1982 Census of Manufactures publication discusses the resistance rule.

Industry code resistance - The production of many establishments is so evenly divided among two industry-determining product groups or more that the industry codes could change from year to year (industry codes can be based on less than half of the total value if there are three groups or more). In the ASM, establishments had always been prevented from shifting back and forth among industries due to minor shifts in product mix in the years between censuses by the application of a "resistance formula" in assigning industry classifications. In census years such resistance was not applied.

A resistance formula of the ASM type was first used in the 1963 Census of Manufactures. In the 1982 census, the formula was applied only to establishments included in the 1981 ASM sample panel with certainty (that is, included with a probability of "1"). In general, these certainty cases were establishments of companies with at least one manufacturing establishment with 250 employees or more.

The formula recognizes the conflicting need to maintain continuity in the establishment composition of an industry to measure change and the need to allow establishments to be reclassified to measure the current composition of the industry.

In the 1982 census, the industry classification of a certainty establishment was allowed to change from that assigned in 1981 under one of the following conditions:

a. The value of the 1982 primary product constituted 60 percent or more of its total value of product shipments.

b. The value of 1982 primary products, while less than 60 percent of the total, was at least twice the value of products which had determined the 1981 industry code.

c. The value of primary products, while not meeting either of the two above conditions, had been the largest group of products for at least two years, i.e., exceeded the value of the 1980 primary industry's products in both 1982 and 1981 by at least 20 percent. 


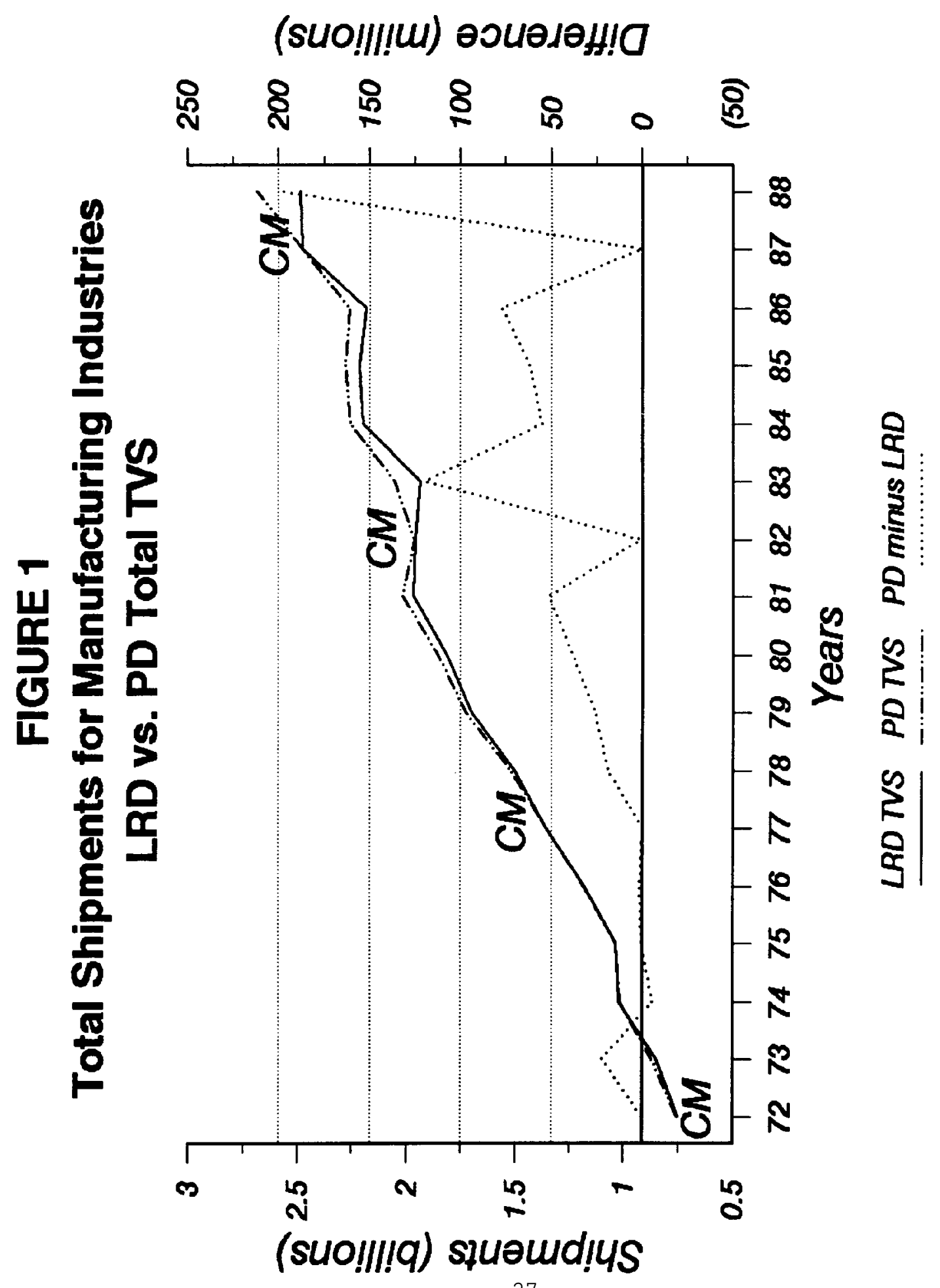




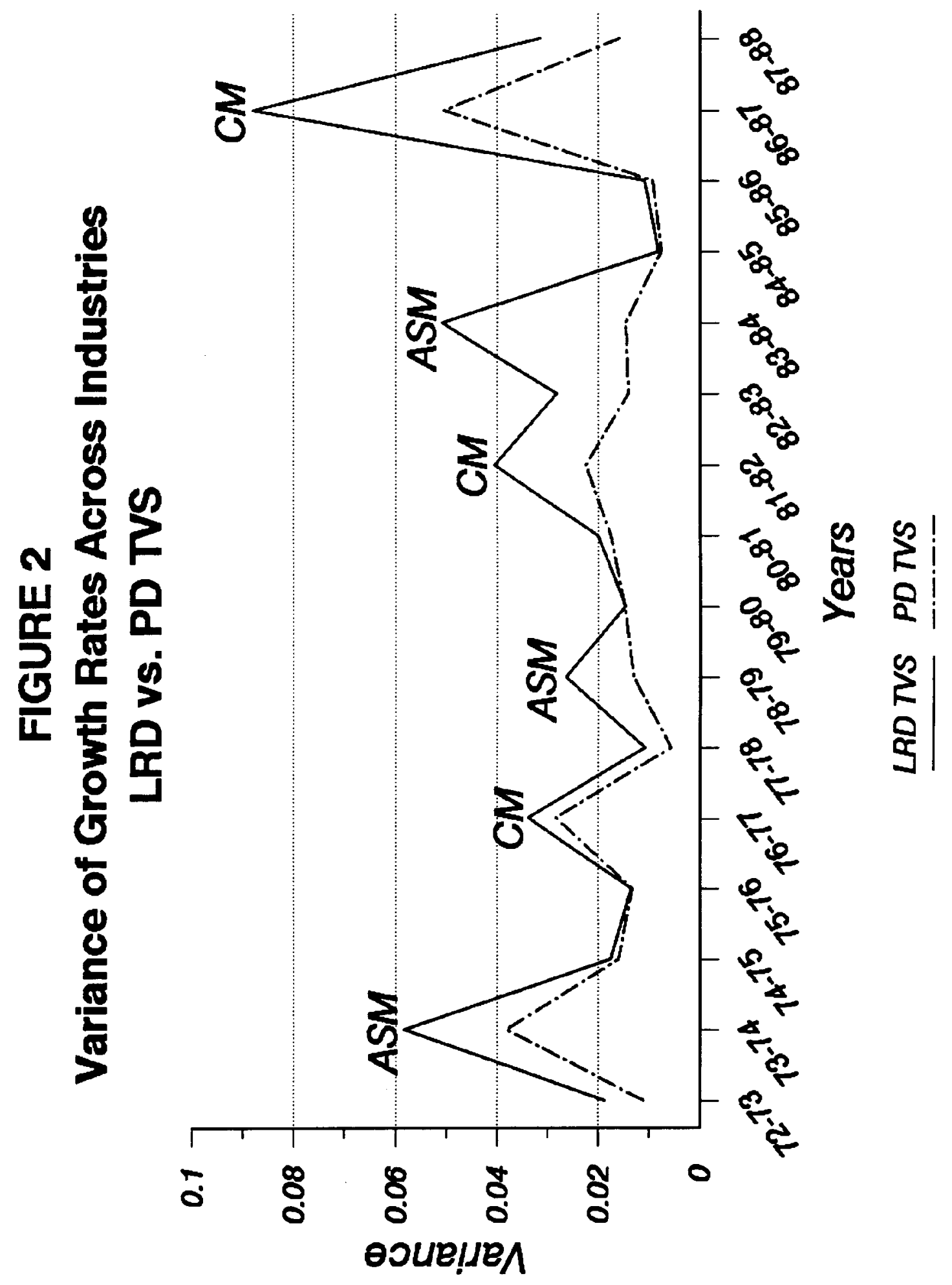




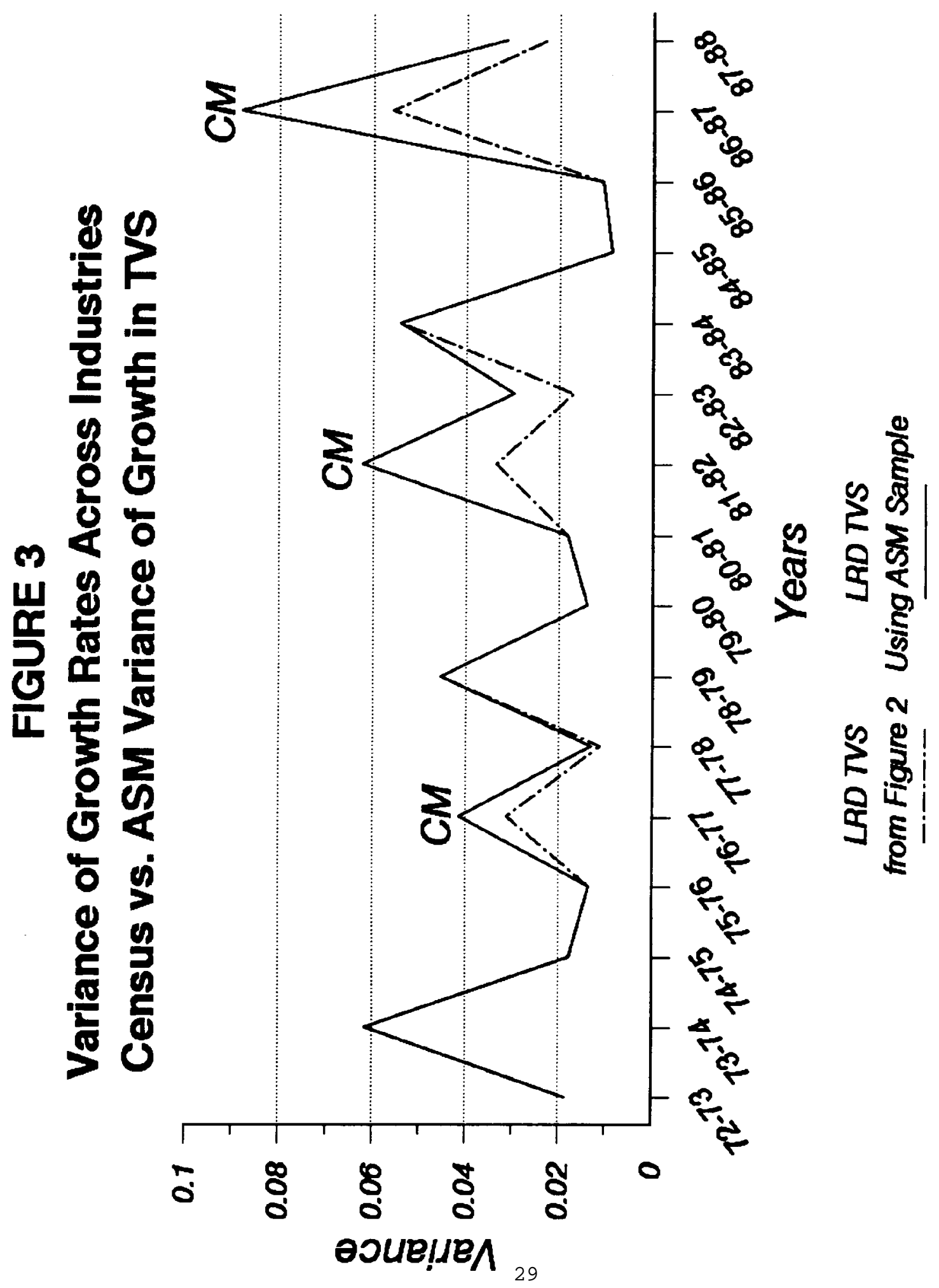

